\title{
Analysis on the Combination of Activity-Based Costing and Balanced Scorecard
}

\author{
Liu ShuLiang \\ Economic Management Institute \\ North China Electric Power University (BaoDing) \\ Hebei province, China \\ 1231s1@163.com
}

\author{
WuJing \\ Economic Management Institute \\ North China Electric Power University (BaoDing) \\ Hebei province, China \\ 2296924427@qq.com
}

\begin{abstract}
At present, the activity-based costing (ABC) and the Balanced Scorecard (BSC) application in the enterprise management, most are analyzed alone on them, very few combine the two together for comparison, but the actual life experience shows that there is a certain correlation between $\mathrm{ABC}$ and BSC, the combination of the two companies to use the effect of cost management is more and more obvious. Based on the simple introduction of activity-based costing and the balanced scorecard, this paper analyzes the feasibility of the combination of the two, and explains the necessity of the use of the combination of the two In today's complex and changeable, the pursuit of innovation in the social environment, the use of the combination of the two will increase the use of each other, and better for enterprise management services.
\end{abstract}

Keywords-Activity-Based Cost Method; Balanced Scorecard; Feasibility; Necessity

\section{INTRODUCTION}

$\mathrm{ABC}$ has since raised, widely recognized in theoretical circles, is regarded as one of the major achievements in the development of contemporary management accounting, also be regarded as a new generation of revolutionary cost management system, the balanced scorecard is a new performance management system, it will be the result of static (financial index) and behavior process dynamic (non-financial index) combined. ${ }^{[1]}$ Not only provides a new and effective framework for the performance management system, but also provides ideas and methods for the establishment of the system between strategic management and performance appraisal. This article carries on the analysis of the relationship between the $\mathrm{ABC}$ and $\mathrm{BSC}$ combination and the feasibility and necessity of combining the case described, further confirmed that only the organic combination of the two, in order to improve the management level of the enterprises in china. ${ }^{[2]}$

\section{INTRODUCTION OF ABC AND SBC}

Activity-Based costing and balanced scorecard is the two new content of management accounting in the last two decades. It has been a hot research topic in domestic and foreign experts and scholars. activity-based costing and balanced scorecard not only enrich the theory and methods of management accounting, but also play a positive role in improving the practice of management accounting. ${ }^{[3]}$

Firstly, the activity-based costing method (activity- based costing, referred to as $\mathrm{ABC}$ ) to give a clear explanation of
Robin Cooper of Harvard University and Robert Kaplan (1988), it is in the beginning as a method used to calculate the cost of a more accurate one is the allocation of indirect cost and auxiliary resources to a more accurate operation, production cost process, product, service and customer in the calculation. Later, with the wide application of the development and operation cost calculation method, it contains the idea of being gradually applied to cost management, as a management philosophy that activity-based management (activity-based management, referred to as ABM). ${ }^{[4]}$

The balanced scorecard is to improve the traditional performance evaluation system by Robert Kaplan of the Harvard University and David Norton (1992) first proposed, is used to express the relationship varied and goals, these goals are based on the production capacity of enterprises in the competition and must achieve in the production of technological innovation in the competition. The Balanced Scorecard into decision tasks and objectives and targets, consists of four parts: financial customer, internal business process and learning and growth, which in the traditional performance evaluation based on a financial and an increase of three, and the enterprises can according to their own characteristics and the need to increase or decrease the objectives and targets, balanced scorecard the card is also a management philosophy from the essence, should not rigidly adhere to the form, and should be applied flexibly, make enterprise management service.

\section{FEASIBILITY ANALYSIS OF THE COMBINATION OF ABC AND} $\mathrm{BSC}$

\section{A. Characteristics of BSC and ABC}

\section{1) Advantages and disadvantages of BSC model}

Advantages:(1)For the enterprise to provide financial and non-financial dimensions of multidimensional performance evaluation perspective.(2)It points out the relationship between the various dimensions. "Learning and growth" is the core, "internal process" is the foundation, "customer" is the key factor, "finance" is the final outcome measures. (3)Emphasis on the long-term, systematic, comprehensive, continuous evaluation. With the prominent strategic goals and motivation, encourage employees to create and realize the goal, can effectively form the incentive mechanism of enterprises.(4)The emphasis of dynamic management, timely tracking, timely feedback. 
Disadvantages: (1) Only from the macro perspective, it provides a comprehensive evaluation of the point of view, but the macro indicators of the decomposition and refinement method does not indicate that the lack of operational performance for specific evaluation objects.(2)The enterprise is a profit as the goal, the Balanced Scorecard does not emphasize the relationship between wood and income, does not emphasize the cornerstone of the cost of the status.

\section{2) Advantages and disadvantages of $A B C$ model}

Advantages: Application of $\mathrm{ABC}$ model in cost management, the main method of enterprise as indirect costs determined, compared with the traditional accounting system is essentially different, to work as the core, emphasizes the cost functions and structure, reflects the new ideas of modern cost management, but the ABC model is essentially based on the financial performance evaluation process, not comprehensive reflect the dimensions of enterprise performance.

Disadvantages: (1) According to the operation of the existing process to divide the work, there is no future situation is expected and assessment, lack of feedforward, resulting in a new situation occurs only when the job can be carried out in a passive adjustment. (2) Cost accounting center can only passively accept the cost of the distribution of the cost, do not emphasize the subjective initiative of people. (3) The activitybased costing can't stand on the high point of the enterprise strategy to consider the cost problem.

\section{B. Correlation of the two methods}

Is the cost of the enterprise cost management as a management elements, achieve the strategic goal of enterprise resource utilization cost, is to eliminate the work waste from the horizontal, while the $\mathrm{ABC}$ method is based on the operation of the subdivision, determine the operating cost base, the corresponding tracking operation, as far as possible to eliminate the "value-added operations", "improvement of value-added operations" scientific and effective and high decision-making; from the vertical perspective, the development of enterprises, the cost management means, the goal is to realize the enterprise strategy, ${ }^{[5]}$ and $\mathrm{BSC}$ is the enterprise strategy specific to the customer, internal processes, learning and financial development in 4 dimensions, the behavior of the whole organization consistent serve strategic goals. $^{[6]}$

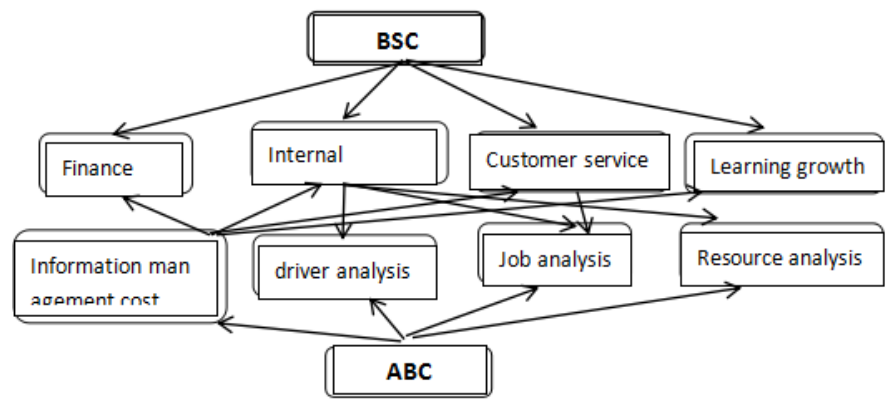

Fig. 1. $\mathrm{BSC}$ and $\mathrm{ABC}$ association graph

Through the analysis of advantages and disadvantages of $\mathrm{ABC}$ and $\mathrm{BSC}$ is not difficult to find that both the $\mathrm{ABC}$ and BSC of the advantages and disadvantages of the opposite:
ABC's disadvantage is the lack of contact with the enterprise strategy, so there is no direction, while the BSC is precisely the enterprise strategy execution tool, as a strategic carrier; the disadvantage is that the BSC did not work as a starting point for analysis of the problem, which can't effectively manage the process and ability of enterprises, and $\mathrm{ABC}$ is just to work as the basic object of management, a management tool of comprehensive management of enterprise operation and process. ${ }^{[7]}$ Therefore, the combination of ABC and BSC these two management tools to use, so that they achieve complementary advantages, so as to bring greater help to the management of enterprises.

In summary, the Balanced Scorecard in the macro guidance to make up for the lack of activity-based costing, activity-based costing to make up for the deficiencies of the BSC in the microscopic details, both at different levels play a role of cost management, cost management and optimization.

\section{CASE ANALysis}

The combined use of BSC--ABC, help enterprises to plan, cost control, accounting and analysis, the use of BSC is to help enterprises to "do things right" the effective management tools, the use of $\mathrm{ABC}$ is to help enterprises in the practice of scientific cost accounting, so as to provide the basis for the scientific management of enterprises cost, is the object of analysis and control do things right ", and will not appear" although the cost is calculated, but I do not know how to use "phenomenon. In the following example: if there is a cost center is engaged in the production preparation and operation of machinery, through these two operations, the production of A, B, C three products. Due to the improvement of production process and other reasons, the number of preparation of $\mathrm{A}$ products is reduced, and the processing method of $A B C$ and the processing method in BSC-ABC mode are analyzed.

\section{A. ABC Processing Method}

The cost of the $\mathrm{ABC}$ method separately, cost accounting and measurement center, cost sharing expenses, production preparation and operation of machinery operation, as shown in Fig. 2.

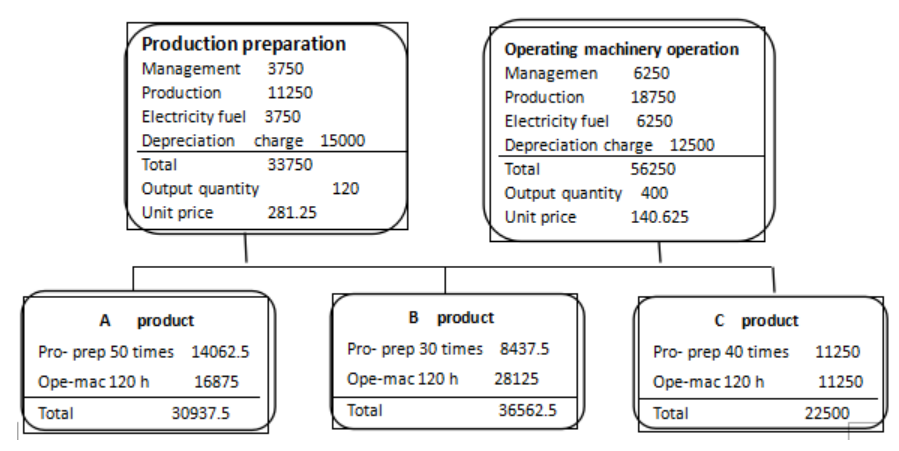

Fig. 2. ABC plan data

Assuming that the income of products is 33000 yuan, B product revenue is 38000 yuan, $\mathrm{C}$ product revenue is 23300 yuan, the profit is shown in Table 1. 
TABLE I. $\quad$ ABC UNDER THE PLAN EARNINGS

\begin{tabular}{|c|c|c|c|c|}
\hline & A product & B product & C product & Total \\
\hline Income & 33000 & 38000 & 23300 & 94300 \\
\hline cost & 30937.5 & 36562.5 & 22500 & 90000 \\
\hline profit & 2062.5 & 1437.5 & 800 & 4300 \\
\hline
\end{tabular}

Hypothesis, improvement of production process and other reasons, the preparation of products is reduced from 50 times to 40 times, reduced by 10 times. Due to electricity, fuel costs are a change in the cost of production is reduced by 10 times, the corresponding reduction in electricity, fuel costs 312.5 yuan. Of course, in addition to reducing power, fuel costs, other costs of production preparation work is not reduced due to work, so that each to make a preparation cost higher than planned, resulting in cost and profit of each product are changed. $\mathrm{ABC}$ method to improve the cost of accounting process, as shown in Fig. 3.

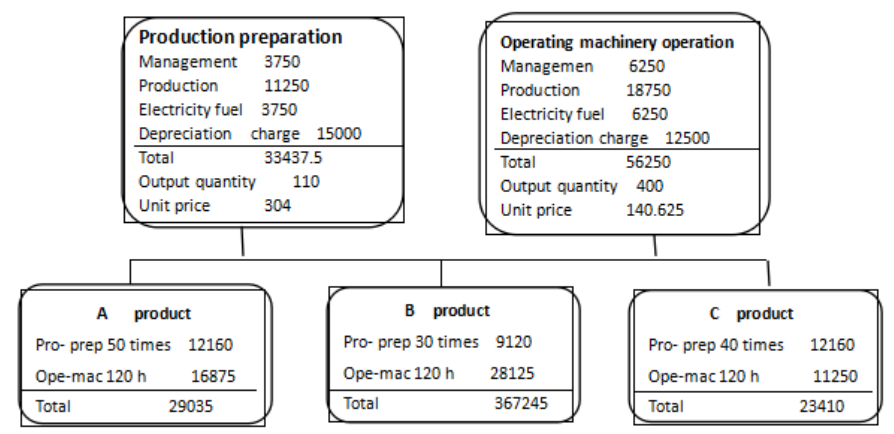

Fig. 3. Fig. $3 \mathrm{ABC}$ actual cost data

Under the ABC accounting system, due to the cost of B, A, $\mathrm{C}$ product changes, resulting in a change in profit. From table 2 we can see that the actual situation and planning of small differences, resulting in a sharp increase in profits for $\mathrm{A}$ products, while $\mathrm{B}$ and $\mathrm{C}$ products, profit margins, and even $\mathrm{C}$ profit is negative, which is obviously not reasonable.

TABLE II. ACTUAL EARNINGS UNDER ABC

\begin{tabular}{|c|c|c|c|c|}
\hline & A product & B product & C product & Total \\
\hline Income & 33000 & 38000 & 23300 & 94300 \\
\hline cost & 29035 & 3724.5 & 23410 & 89690 \\
\hline profit & 3965 & 755 & $(110)$ & 4620 \\
\hline
\end{tabular}

From the above examples, illustrates the deficiency ABC method: only on the activity tracking, measurement work and the cost objective cost management, its scope in the operation level, lead to the emergence of new situation, cost accounting center can only passively accept the distribution costs down, resulting in cost distortion: the initiative does not emphasize a person that cannot stand in the height of the corporate strategy cost management.

\section{B. BSC-ABC mode processing method}

In the above example, specifically, enterprises in the period before according to the experiences of the same industry, the history data and enterprise development goals were determine the unit cost and unit operation for mechanical operation cost expectations, assuming unit ready operating costs expected value of 300 yuan, a single operating machinery cost expectations for 145 yuan.
Fig. 2, table 3 shows that the process improvement, resulting in the unit to prepare operating costs from.25 28I yuan to 304 yuan, and ultimately produce a negative profit of $\mathrm{C}$ products, which is obviously unreasonable. The principle of due process improvement by A products operation times is reduced from 50 to 40 , not only is the power, reduce fuel costs 312.5 yuan, also means to reduce the artificial, which does not require the number of the original amount.

In $\mathrm{BSC}-\mathrm{ABC}$ mode, the unit preparation and mechanical unit operation expectations, department or cost center staff will play the subjective initiative to expectations, and because of the BSC management, a product preparation process improvement before and after a gap of 10 times, the number of enterprises can adjust cost center. The above examples of specific performance as the cost of the center of the wage reduction, that is, to reduce the management staff wages 312.5 yuan, 937.5 yuan to reduce production staff wages. In BSC-ABC mode, the cost of collection, calculation and measurement as shown in Fig. 4, the profitability is shown in Table 3.

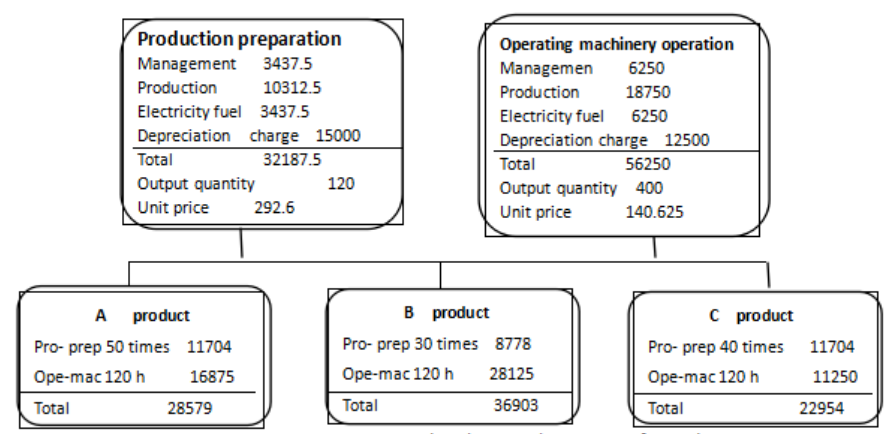

Fig.4 ABC BSC- under the actual situation of cost data

TABLE III. THE ACTUAL PROFITABILITY UNDER ABC-BSC

\begin{tabular}{|c|c|c|c|c|}
\hline & A product & B product & C product & Total \\
\hline Income & 33000 & 38000 & 23300 & 94300 \\
\hline cost & 28579 & 36903 & 22954 & 88436 \\
\hline profit & 4421 & 1097 & 346 & 5864 \\
\hline
\end{tabular}

Fig. 4, table 3 shows that in BSC-ABC mode, the management according to the various conditions timely adjustment of personnel structure, guide the collection and calculation of the cost of the real, reflect the cost of enterprise, to provide real data for enterprise management. Therefore, the author thinks that the enterprise implementation of management of the logistics cost of BSC-ABC model is feasible, necessary and effective, will help guide the correct collection cost.

\section{CONCLUSION}

Although the combination of activity-based costing and the balanced score card is feasible and necessary, there are some places that need attention or improvement:

(1)Combination of enterprise strategy, the decomposition of the strategic target is based on the beginning of BSC-ABC enterprise cost management mode, but also the focus, if the strategic objectives of the decomposition are unreasonable, resulting in the future work is in vain. 
(2)The study of enterprise cost management is the basic point of how to reduce the cost of the enterprise, with strong practical characteristics. But in fact the enterprise cost involved is complex, dynamic and uncertain characteristics, so I think the application of system dynamics. The organic combination of them to solve the problems existing in the enterprise together more dynamic and.

Activity-based costing and balanced scorecard as a new type of enterprise management methods, in terms of cost management has its own advantages. At the same time, both have similarities, in the implementation of the process is complementary, so companies should be used in combination. ${ }^{[8]}$ On the one hand, the decision-making related information provided by $\mathrm{ABC}$, on the other hand, using the balance scorecard implementation of performance evaluation and decision, the formation of a complete system of strategic management, the maximization of corporate value creation. ${ }^{[9]}$

\section{REFERENCES}

[1] Chen Chao, Sun Jianqiang. An analysis of the combination of ActivityBased costing and balanced scorecard [J]. Journal of Ocean University of China, 2013,03:35-37.

[2] Yan Mei. The organic combination of the Balanced Scorecard and the Activity-Based costing [J]. China's township and village enterprises accounting, 2015,10:27-28.

[3] Chen Shina, Zheng Long. The combination of Activity-Based costing and balanced scorecard in strategic management [J]. Logistics technology Operation, 2009,02:41-44.

[4] Wan righteousness and $\mathrm{Li} \mathrm{Li}$. Combined with the research on the [J]. Accounting BSc and ABC, 2010,06:4-6.

[5] Li Jie, Xia Yunfei, Chen Chen. The combination of Activity-Based costing and balanced scorecard in the cost management of manufacturing enterprises [J].Finance and accounting communication, 2011, 17:136-137.

[6] Tao ting. Job management and balanced scorecard combined with the application of [J]. (A friend of the accounting under 2006,06:67-68.).

[7] Zhang Qian. On Activity-Based costing and balanced scorecard management concept of the same sex and its organic combination [J]. shopping mall modernization, 2006

[8] Huang Junjie. On a combined analysis of [J]. financial sector costing and balanced scorecard (Academic Edition), 2008

[9] Wang Fenting, Liu Qunling, Song Zhenhui. Cholily, on the principle of $\mathrm{ABC}$ extended balanced scorecard system [J]. Chinese management information, 2012,09:78-83. 